Original Article - Clinical Science

\title{
Epidemiology of episcleritis and scleritis in urban Australia
}

Louisa P. Thong MBBS, ${ }^{1,2}$ Sophie L. Rogers MEpi, ${ }^{1,3}$ Colby T. Hart MBBS, ${ }^{1}$ Anthony J . Hall FRANZCO MD ${ }^{2,4}$ and Lyndell L. Lim FRANZCO DMedSci ${ }^{1,3}$

1. Centre for Eye Research Australia, The Royal Victorian Eye and Ear Hospital, Victoria, Australia

2. Monash University, Melbourne, Victoria, Australia

3. Ophthalmology, University of Melbourne, Department of Surgery, Melbourne, Victoria, Australia

4. Department of Ophthalmology, Alfred Hospital, Melbourne, Victoria, Australia

Correspondence: A/Prof Lyndell L. Lim, Centre for Eye Research Australia, University of Melbourne, Royal Victorian Eye and Ear Hospital, 32 Gisborne Street, East Melbourne, Victoria 3002 Australia

Email: limllp@unimelb.edu.au

Short running title: Episcleritis and scleritis in Australia Received 8 August 2019; accepted 4 April 2020 Funding sources / Financial disclosure: Lyndell L. Lim is supported by a National Health \& Medical Research Council Early Career Fellowship (\#1109330). The Centre for Eye Research Australia receives Operational Infrastructure Support from the Victorian Government.

This is the author manuscript accepted for publication and has undergone full peer review but has not been through the copyediting, typesetting, pagination and proofreading process, which may lead to differences between this version and the Version of Record. Please cite this article as doi: $10.1111 /$ ceo.13761

This article is protected by copyright. All rights reserved. 
Conflict of interest: Lyndell. L. Lim has worked on advisory boards for AbbVie, Bayer and Allergan. She has received research support from Novartis, Bayer and Allergan and has received lecture fees from AbbVie, Novartis and Allergan.

Anthony J. Hall has worked on advisory boards for AbbVie and Allergan. He has received research support from Novartis and has received lecture fees from AbbVie.

\section{Abstract}

I mportance: The epidemiology of episcleritis and scleritis in Australia is largely unknown.

Background: To determine incidence, prevalence and clinical characteristics of episcleritis and scleritis in Melbourne.

Design: Retrospective longitudinal study.

Participants: Patients aged $\geq 18$ years with episcleritis or scleritis seen at the Royal Victorian Eye and Ear Hospital from November 2014 to October 2015.

Methods: Medical record review confirmed clinical diagnosis and characteristics. Incidence and prevalence were calculated using estimates of the adult population in areas of Melbourne with $\geq 30$ ocular presentations/year to the emergency department.

Main Outcome Measures: Diagnosis of active episcleritis or scleritis, aetiology, ocular complications and treatments.

Results: From a general population of 3,408,068, we confirmed 149 new and 23 pre-existing cases of active episcleritis, and 35 new and 23 pre-existing cases of active scleritis. Incidence per 100,000 person-years was 4.4 (Cl 3.7-5.1) for episcleritis and 1.0 (Cl 0.7-1.4) for scleritis, while 12-month prevalence was 5.1 (Cl 4.3-5.9) and 1.7 (1.3-2.2) per 100,000 persons, respectively. Systemic disease was associated with $10 \%$ of episcleritis compared with $34 \%$ of scleritis ( $p<0.001)$. Ocular complications were seen in $3 \%(6 / 184)$ of episcleritis eyes and $44 \%(32 / 72)$ of 
scleritis eyes, with the commonest being anterior uveitis (12/72) and ocular hypertension (14/72). At presentation, scleritis patients were commonly treated with oral non-steroidal anti-inflammatory drugs (60\%) and prednisolone (19\%). By 12 months, $24 \%$ of scleritis patients required immunosuppressants.

Conclusion and relavance: Rates of episcleritis and scleritis in our single-centre Australian study were low. Episcleritis was usually benign, whereas scleritis had increased ocular complications and systemic disease.

Keywords: Scleritis, epidemiology, incidence

\section{I NTRODUCTI ON}

Episcleritis and scleritis are forms of ocular inflammation that can have similar acute presentations. Episcleritis is typically benign and superficial, whereas scleritis is often more severe with inflammation extending to the deep scleral coat of the eye. Scleritis may also be vision threatening and is associated with a systemic disease in up to $50 \%$ of cases. ${ }^{1}$ It is important to understand the epidemiology of these two conditions to enable accurate diagnosis, investigation and treatment.

Previous population-based studies conducted in the United States (U.S) report episcleritis and scleritis as uncommon diseases, with incidence estimates varying from 21.7 to 41.0 per 100,000 person-years for episcleritis and 3.4 to 4.1 per 100,000 person-years for scleritis. ${ }^{2,3}$ Since the clinical presentations of patients included in these published estimates were up to 20 years ago, the current state of the incidence and prevalence of these conditions is uncertain. Further, to our knowledge, no studies have evaluated the epidemiology of episcleritis or scleritis in Australia. 
We aimed to determine the incidence and prevalence of episcleritis and scleritis in a well-defined cohort of Melbourne, Australia and describe their clinical characteristics.

\section{METHODS}

This was a retrospective longitudinal single centre study that adhered to the tenets of the Declaration of Helsinki and was approved by the Royal Victorian Eye and Ear Hospital (RVEEH) Human Research Ethics Committee. In Melbourne, Australia's second largest city, the RVEEH provides specialised tertiary care with the only dedicated ophthalmic emergency department (ED) and Ocular I mmunology Clinic (OIC). All patients with episcleritis or scleritis seen at the RVEEH from November 1 , 2014 through to October 31, 2015, inclusive, were identified from a diagnostic code search of the ED electronic medical record database and through manual searching of the diagnostic coding of all patients who attended the OIC during this period (Supplemental Figure 1). 


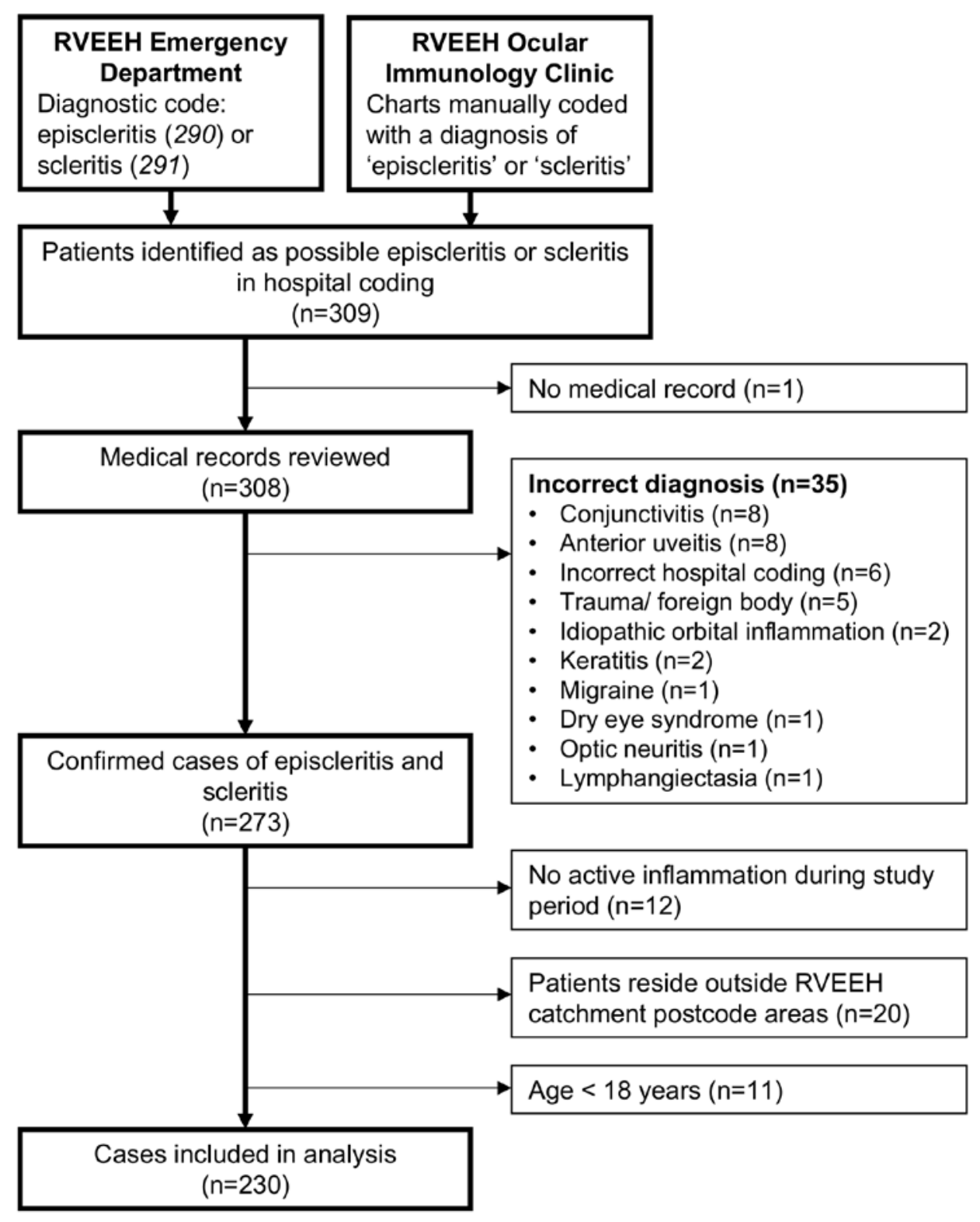

Supplemental Figure 1. Identification of confirmed, active episcleritis and scleritis cases in the adult resident population of Melbourne serviced by the Royal Victorian Eye and Ear Hospital (RVEEH) 
Chart review was conducted and consecutive patients with a confirmed diagnosis of episcleritis or scleritis were included in this study. Patients under 18 years old are not commonly managed at the RVEEH and so have been excluded from this study, but their exclusion is likely to have a minimal effect on our estimates given very low reported rates of both conditions in this age group. ${ }^{2,3}$ Cases of episcleritis and scleritis were defined by modified Honik clinical criteria, ${ }^{3}$ and were further confirmed by the final clinical diagnosis given to each case after follow-up in the specialised OIC of the RVEEH. Independent adjudication by a uveitis subspecialist (L.L) was used to determine the final clinical diagnosis in cases not seen in the $\mathrm{OIC}$, or where the diagnosis as per the modified Honik criteria was discordant with the diagnosis in the patient record.

Episcleritis was defined as the injection of superficial vessels with minimal pain and tenderness as per modified Honik criteria. Further evidence of episcleritis was the blanching of inflamed red vessels with either $2.5 \%$ or $10 \%$ phenylephrine. The definition of scleritis included three or more of the following: (1) injected vessels with a deep red or violaceous hue, (2) severe pain that interfered with sleep or was associated with significant tenderness on palpation, (3) the absence of blanching of injected vessels with instillation of $2.5 \%$ or $10 \%$ phenylephrine and (4) chronicity of disease, defined as persistent active inflammation during at least 1 month of followup after initial presentation or prompt relapse after discontinuing treatment.

Chronicity of disease was included in this definition due to the potential similarities in appearance between episcleritis and scleritis on presentation and the persistent/ recurrent nature of scleritis evident on retrospective review and manual confirmation of diagnosis. ${ }^{4,5}$ In the case of posterior scleritis, diagnosis was based on suggestive fundus findings in combination with a positive T-sign on B-scan ultrasonography or other radiographic confirmation. 
Episcleritis and scleritis were divided into infectious and non-infectious cases. Noninfectious episcleritis was classified into simple or nodular disease. Non-infectious scleritis was divided into anterior and posterior subtypes. Anterior scleritis was further classified into diffuse, nodular, necrotising and scleromalacia perforans. Posterior scleritis with concurrent features of anterior inflammation were still categorised under posterior scleritis. Disease subtype classification was performed per patient due to the lack of observed independence of each eye in the same patient.

Demographic data retrieved included age, gender and postal code. Clinical data retrieved were aetiology/ systemic disease associations and per-eye ocular complications. Due to the varied disease course between episcleritis and scleritis, we compared ocular complications during the first 12 months of disease from the patient's initial presentation to the RVEEH. Anterior segment ocular complications assessed were corneal involvement, anterior uveitis, cataract, ocular hypertension and scleral thinning. Corneal involvement was divided into keratitis with an intact epithelium or peripheral ulcerative keratitis (PUK), which involved stromal loss and epithelial breakdown. Anterior uveitis was diagnosed as the presence of 1+ cells or worse in the anterior chamber in keeping with previous studies. ${ }^{6}$ Ocular hypertension (OHT) was defined as an intraocular pressure greater than $24 \mathrm{mmHg}$. Posterior segment ocular complications assessed were serous retinal detachment, cystoid macular oedema, vitritis, optic nerve head swelling and choroidal folds. Treatment during the first 12 months of disease from initial presentation to the RVEEH were also retrieved for all scleritis patients and compared across each different subtype.

The primary outcome measure of this study was a new or pre-existing diagnosis of active episcleritis or scleritis presenting during the study period. All confirmed cases 
of episcleritis and scleritis were classified into one of three categories: incident, active prevalent or inactive prevalent. Incident cases were defined as patients who received a new diagnosis of episcleritis or scleritis between November 1, 2014 and October 31, 2015, inclusive. Active prevalent cases were defined as patients presenting with active episcleritis or scleritis during the study period but who were initially diagnosed prior to November 1, 2014. Inactive prevalent cases, defined as patients with a history of episcleritis or scleritis but with no active inflammation during the study period, were excluded from this study.

Our method for obtaining an estimate of the mid-period population denominator has been described elsewhere. ${ }^{7}$ Briefly, the RVEEH catchment was defined by geographic areas from whence there had been 30 or more ocular ED presentations in a 1-year period (J anuary 1, 2014 to December 31, 2014). People aged less than 18 years were removed from the RVEEH catchment denominator. The RVEEH does manage paediatric patients but the majority of paediatric patients and especially the majority of paediatric patients with underlying rheumatological disease are managed at a nearby specialised paediatric hospital in Melbourne, making our data unreliable for this age group. Active episcleritis or scleritis patients were included as cases in our incidence or prevalence calculations if they lived in a postal code area in which at least $10 \%$ of the postal code area's population reside in an RVEEH-catchment statistical area. Any patients who resided outside of the RVEEH catchment area were excluded from incidence and prevalence calculations and aetiology studies outlined herein.

All statistical analyses were performed using Stata IC 14.2 (StataCorp LLC, College Station, TX). Incidence rates per 100,000 person-years and 12-month period prevalence rates per 100000 persons were calculated using mid-period estimates for the adult resident population of Melbourne areas serviced by RVEEH as defined 
above. Incidence and prevalence were reported as age and gender stratified rates with Agresti-Coull 95\% confidence intervals ( $\mathrm{Cl}$ ). In age-gender strata with zero cases, the upper limit of the $\mathrm{Cl}$ was calculated using the Hanley and Lippman-Hand method. Descriptive statistics were expressed as medians with interquartile ranges (IQR) for continuous data. Continuous variables were compared between disease groups using the Wilcoxon rank-sum test, and categorical data compared using Fisher's exact test. A p value $<0.05$ was considered statistically significant.

\section{RESULTS}

\subsection{I ncidence and prevalence}

The mid-period adult resident population of the RVEEH-serviced area of Melbourne was 3,408,068 people. A total of 309 patient records were initially identified and after chart review, we confirmed 230 patients with active episcleritis or scleritis who resided within the defined RVEEH-serviced area. Demographic characteristics are shown in Table 1. Reasons for exclusion are outlined in Supplemental Figure 1. 
Table 1: Baseline demographic data for all episcleritis and scleritis patients in the Melbourne population

\begin{tabular}{|c|c|c|c|}
\hline Characteristic & $\begin{array}{l}\text { Episcleritis } \\
(\mathrm{n}=172)\end{array}$ & $\begin{array}{l}\text { Scleritis } \\
(\mathrm{n}=58)\end{array}$ & P value $^{\dagger}$ \\
\hline Female, n (\%) & $97(56)$ & $41(71)$ & 0.063 \\
\hline Age, median (IQR), years & $43.5(36.4-57.3)$ & $46.0(36.0-57.1)$ & 0.997 \\
\hline Age category [years], n (\%) & & & 0.011 \\
\hline $18-24$ & $3(2)$ & $6(10)$ & \\
\hline $25-44$ & $90(52)$ & $22(38)$ & \\
\hline $45-64$ & $57(33)$ & $25(43)$ & \\
\hline $65+$ & $22(13)$ & $5(9)$ & \\
\hline $\begin{array}{l}\text { Age at diagnosis, median (IQR), } \\
\text { years }\end{array}$ & $43.0(35.5-55.9)$ & $44.6(32.9-56.0)$ & 0.781 \\
\hline $\begin{array}{l}\text { Duration of follow-up, months, } \\
\text { median (IQR) }\end{array}$ & $0.4(0-1.9)$ & $23.0(2.4-68.8)$ & $<0.001$ \\
\hline \multicolumn{4}{|c|}{$\begin{array}{l}{ }^{+} \mathrm{P} \text { values refer to the difference between episcleritis and scleritis groups as } \\
\text { determined by Fisher's exact test for age groups and Wilcoxon rank-sum test fol }\end{array}$} \\
\hline
\end{tabular}

A total of 149 new and 23 pre-existing cases of active episcleritis were confirmed, yielding an incidence of 4.37 (Cl 3.72-5.13) per 100,000 person-years and a 12 month period prevalence of 5.05 ( $\mathrm{Cl}$ 4.34-5.86) per 100,000 persons. Females aged between 25 to 44 years had a higher incidence $(p=0.03)$ and prevalence $(p=0.02)$ of episcleritis compared with males of the same age (Table 2). However, the incidence of episcleritis decreased in females with increasing age, whereas an opposing trend was seen in males, where the highest rate of episcleritis was in those aged 65 years and older. 
Table 2: Episcleritis incidence and 12-month period prevalence by age and gender in the Melbourne population

Incidence $(\mathrm{Cl})^{\dagger}$ per 100000 person-years

\begin{tabular}{lcccccc}
\hline Age, years & \multicolumn{2}{c}{ Female } & \multicolumn{2}{c}{ Male } & \multicolumn{2}{c}{ Total } \\
\hline & $\mathbf{N}^{\ddagger}$ & Rate $(\mathbf{C l})^{\dagger}$ & $\mathbf{N}^{\ddagger}$ & Rate $\mathbf{( C l})^{\dagger}$ & $\mathbf{N}^{\ddagger}$ & ${\text { Rate } \mathbf{( C I})^{\dagger}}^{\dagger}$ \\
\hline $18-24$ & 2 & $0.92(0.02,3.58)$ & 1 & $0.44(0,2.76)$ & 3 & $0.67(0.13,2.08)$ \\
\hline $25-44$ & 50 & $7.35(5.56,9.71)$ & 29 & $4.31(2.98,6.22)$ & 79 & $5.84(4.68,7.28)$ \\
\hline $45-64$ & 25 & $4.80(3.22,7.12)$ & 21 & $4.24(2.73,6.52)$ & 46 & $4.53(3.38,6.05)$ \\
\hline $65+$ & 6 & $1.85(0.74,4.15)$ & 15 & $5.57(3.29,9.27)$ & 21 & $3.54(2.28,5.44)$ \\
\hline Total & 83 & $4.76(3.84,5.91)$ & 66 & $3.96(3.11,5.05)$ & 149 & $4.37(3.72,5.13)$ \\
\hline
\end{tabular}

Period prevalence $(\mathrm{Cl})^{\S}$ per 100000 persons

\begin{tabular}{|c|c|c|c|c|c|c|}
\hline & \multicolumn{2}{|r|}{ Female } & \multicolumn{2}{|r|}{ Male } & \multicolumn{2}{|r|}{ Total } \\
\hline & $\mathbf{N}^{\ddagger}$ & Rate $(\mathrm{Cl})^{\S}$ & $\mathbf{N}^{\ddagger}$ & Rate $(\mathrm{Cl})^{\S}$ & $\mathbf{N} \neq$ & Rate $(\mathrm{Cl})^{\S}$ \\
\hline $18-24$ & 2 & $0.92(0.02,3.58)$ & 1 & $0.44(0,2.76)$ & 3 & $0.67(0.13,2.08)$ \\
\hline $25-44$ & 57 & $8.38(6.45,10.87)$ & 33 & $4.90(3.47,6.91)$ & 90 & $6.65(5.40,8.18)$ \\
\hline $45-64$ & 32 & $6.15(4.32,8.71)$ & 25 & $5.05(3.38,7.49)$ & 57 & $5.61(4.32,7.28)$ \\
\hline $65+$ & 6 & $1.85(0.74,4.15)$ & 16 & $5.94(3.57,9.73)$ & 22 & $3.71(2.42,5.65)$ \\
\hline Total & 97 & $5.56(4.56,6.79)$ & 75 & $4.51(3.59,5.65)$ & 172 & $5.05(4.34,5.86)$ \\
\hline
\end{tabular}

$\dagger$ Incidence rate per 100000 person-years estimated using the midperiod

population residing in Greater Melbourne areas with good coverage by the RVEEH and Agresti-Coull 95\% confidence limits for rate.

₹ Number of cases of confirmed, active episcleritis seen at RVEEH from November 2014 to October 2015.

$\S 12$-month period prevalence rate per 100000 persons estimated using the midperiod population (as above) and Agresti-Coull 95\% confidence limits for rate.

$\mathrm{Cl}, 95 \%$ confidence interval 
For scleritis, there were 35 new and 23 pre-existing active cases, which yielded an incidence of 1.03 (Cl 0.73-1.43) per 100,000 person-years and a 12-month period prevalence of 1.70 (Cl 1.31-2.20) per 100,000 persons. In Table 3, higher incidence and prevalence rates were seen in younger females than males, with no cases of scleritis seen in young males aged 18-24 years. Similarly, there were no new cases of scleritis in people aged 65 years and older and the age-gender interaction was not statistically significant ( $p=0.10$ for incidence and $p=0.07$ for prevalence). 
Table 3: Scleritis incidence and 12-month period prevalence by age and gender in the Melbourne population

Incidence $(\mathrm{Cl})^{\dagger}$ per 100000 person-years

\begin{tabular}{lcccccc}
\hline Age, years & \multicolumn{2}{c}{ Female } & \multicolumn{2}{c}{ Male } & \multicolumn{2}{c}{ Total } \\
\hline & $\mathbf{N}^{\ddagger}$ & Rate $(\mathbf{C l})^{\dagger}$ & $\mathbf{N}^{\ddagger}$ & Rate $(\mathbf{C l})^{\dagger}$ & $\mathbf{N}^{\ddagger}$ & ${\text { Rate }(\mathbf{C I})^{\dagger}}^{\dagger}$ \\
\hline $18-24$ & 3 & $1.38(0.26,4.25)$ & 0 & $0(0,1.54)^{\S}$ & 3 & $0.67(0.13,2.08)$ \\
\hline $25-44$ & 12 & $1.76(0.97,3.12)$ & 2 & $0.30(0.01,1.16)$ & 14 & $1.03(0.60,1.75)$ \\
\hline $45-64$ & 10 & $1.92(0.99,3.59)$ & 8 & $1.62(0.76,3.25)$ & 18 & $1.77(1.10,2.82)$ \\
\hline $65+$ & 0 & $0(0,1.08)^{\S}$ & 0 & $0(0,1.30)^{\S}$ & 0 & $0(0,0.59)^{c}$ \\
\hline Total & 25 & $1.43(0.96,2.13)$ & 10 & $0.60(0.31,1.12)$ & 35 & $1.03(0.73,1.43)$ \\
\hline
\end{tabular}

Period prevalence $(\mathrm{CI})^{\natural}$ per 100000 persons

\begin{tabular}{|c|c|c|c|c|c|c|}
\hline & \multicolumn{2}{|r|}{ Female } & \multicolumn{2}{|r|}{ Male } & \multicolumn{2}{|r|}{ Total } \\
\hline & $\mathbf{N}^{\ddagger}$ & Rate (CI )" & $\mathbf{N} \neq$ & Rate $(\mathrm{Cl})^{q}$ & $\mathbf{N}^{\ddagger}$ & Rate $(\mathrm{Cl})^{9}$ \\
\hline $18-24$ & 6 & $2.75(1.10,6.16)$ & 0 & $0(0,1.54)^{\S}$ & 6 & $1.35(0.54,3.02)$ \\
\hline $25-44$ & 18 & $2.65(1.64,4.21)$ & 4 & $0.59(0.17,1.59)$ & 22 & $1.63(1.06,2.48)$ \\
\hline $45-64$ & 14 & $2.69(1.56,4.56)$ & 11 & $2.22(1.19,4.03)$ & 25 & $2.46(1.65,3.65)$ \\
\hline $65+$ & 3 & $0.93(0.18,2.86)$ & 2 & $0.74(0.01,2.90)$ & 5 & $0.84(0.30,2.03)$ \\
\hline Total & 41 & $2.35(1.73,3.20)$ & 17 & $1.02(0.62,1.65)$ & 58 & $1.70(1.31,2.20)$ \\
\hline
\end{tabular}

$\dagger$ Incidence rate per 100000 person-years estimated using the midperiod population residing in Greater Melbourne areas with good coverage by the RVEEH and Agresti-Coull 95\% confidence limits for rate, unless otherwise indicated.

₹ Number of cases of confirmed, active scleritis seen at RVEEH from November 2014 to October 2015.

$\S$ Confidence limit estimated by the Hanley and Lippman-Hand method.

" 12-month period prevalence rate per 100000 persons estimated using the midperiod population (as above) and Agresti-Coull 95\% confidence limits for rate, unless otherwise indicated.

$\mathrm{Cl}, 95 \%$ confidence interval 
Seventeen patients (17/230; 7\%) had a modified Honik diagnosis discordant with their final clinical diagnosis. All 17 cases were incorrectly classified as scleritis according to the modified Honik criteria and were instead confirmed to have a final clinical diagnosis of episcleritis.

\subsection{Systemic disease associations}

From all 230 cases of active episcleritis or scleritis, only a minority of patients had an underlying aetiology (Table 4). Few infectious causes were identified; one case of syphilitic episcleritis and one patient with scleritis was presumed infectious given their history of a past pterygium excision with beta radiation at the site of their scleritis, which then responded to oral antibiotic treatment. In those with noninfectious episcleritis, most cases were simple (143/172; 83\%) and the rest were nodular (29/172; 17\%). Diffuse anterior scleritis was the most common type of scleritis (34/58; 59\%), followed by nodular (16/58; $28 \%$ ) and posterior scleritis $(8 / 58 ; 14 \%)$. There were no cases of necrotising scleritis or scleromalacia perforans in our study. 
Table 4: Aetiology of episcleritis and scleritis

\begin{tabular}{|c|c|c|c|c|c|c|c|c|}
\hline Aetiology & Episclerit & is $n(\%)$ & & Scleritis & $(\%)$ & & & P value $^{\dagger}$ \\
\hline & $\mathbf{N}$ cases & Simple & Nodular & $\mathbf{N}$ cases & $\begin{array}{l}\text { Diffuse } \\
\text { anterior }\end{array}$ & $\begin{array}{l}\text { Nodular } \\
\text { anterior }\end{array}$ & Posterior & \\
\hline All cases & 172 & 143 & 29 & 58 & 34 & 16 & 8 & 0.063 \\
\hline Age, median (IQR), years & $\begin{array}{r}43.5 \\
(36.4- \\
57.3)\end{array}$ & $\begin{array}{r}45.4(36.6- \\
59.1)\end{array}$ & $\begin{array}{r}40.4 \\
(33.0- \\
44.3)\end{array}$ & $\begin{array}{r}46.0 \\
(36.0- \\
57.1)\end{array}$ & $\begin{array}{r}45.6 \\
(34.0- \\
61.5)\end{array}$ & $\begin{array}{r}46.0 \\
(39.6- \\
55.8)\end{array}$ & $\begin{array}{r}44.0 \\
(29.4- \\
55.5)\end{array}$ & 0.997 \\
\hline Female, n (\%) & $97(56)$ & $79(55)$ & $18(62)$ & $41(71)$ & $23(68)$ & $12(75)$ & $6(75)$ & \\
\hline Idiopathic & $154(90)$ & $128(90)$ & $26(90)$ & $37(64)$ & $20(59)$ & $11(69)$ & $6(75)$ & $<0.001$ \\
\hline Infectious & $1(1)$ & $0(0)$ & $1(3)$ & $1(2)$ & $0(0)$ & $1(6)^{\ddagger}$ & $0(0)$ & 0.442 \\
\hline $\begin{array}{l}\text { Systemic disease, total } \\
(\%)\end{array}$ & $17(10)$ & $15(10)$ & $2(7)$ & $20(34)$ & $14(41)$ & $4(25)$ & $2(25)$ & $<0.001$ \\
\hline Rheumatoid arthritis & $3(2)$ & $3(2)$ & $0(0)$ & $11(19)$ & $8(24)$ & $2(13)$ & $1(13)$ & \\
\hline Relapsing polychondritis & $0(0)$ & $0(0)$ & $0(0)$ & $2(3)$ & $2(6)$ & $0(0)$ & $0(0)$ & \\
\hline $\begin{array}{l}\text { Systemic lupus } \\
\text { erythematosus }\end{array}$ & $0(0)$ & $0(0)$ & $0(0)$ & $1(2)$ & $1(3)$ & $0(0)$ & $0(0)$ & \\
\hline $\begin{array}{l}\text { Inflammatory bowel } \\
\text { disease }\end{array}$ & $5(3)$ & $4(3)$ & $1(3)$ & $2(3)$ & $1(3)$ & $0(0)$ & $1(13)$ & \\
\hline Spondyloarthropathy ${ }^{\S}$ & $1(1)$ & $1(1)$ & $0(0)$ & $2(3)$ & $2(6)$ & $0(0)$ & $0(0)$ & \\
\hline Sarcoidosis & $1(1)$ & $1(1)$ & $0(0)$ & $1(2)$ & $0(0)$ & $1(6)$ & $0(0)$ & \\
\hline Behcet's disease & $1(1)$ & $1(1)$ & $0(0)$ & $0(0)$ & $0(0)$ & $0(0)$ & $0(0)$ & \\
\hline Other" & $6(3)$ & $5(3)$ & $1(3)$ & $1(2)$ & $1(3)$ & $0(0)$ & $0(0)$ & \\
\hline
\end{tabular}

+ P-value comparison between overall groups of episcleritis and scleritis using Fisher exact test

₹ No biopsy with microbiological confirmation but responded to antibiotic treatment

$\S$ Includes psoriatic arthritis (1 simple episcleritis patient), ankylosing spondylitis (1 diffuse anterior scleritis patient) and reactive arthritis (1 diffuse anterior scleritis patient)

" Includes psoriasis without psoriatic arthritis (2 episcleritis [1 simple, 1 nodular] and 1 diffuse anterior scleritis patient), IgA nephropathy (1 simple episcleritis patient), Sjogren's syndrome (1 simple episcleritis patient), autoimmune hepatitis (1 simple episcleritis patient) and rosacea (1 simple episcleritis patient). 
A systemic disease was found in $10 \%$ (17/172) of patients with episcleritis compared with 34\% (20/58) of scleritis ( $p<0.001$; Table 4). Inflammatory bowel disease (IBD) was the most common association with episcleritis (5/172; $3 \%)$, followed by rheumatoid arthritis (RA) (3/172; 2\%). A systemic diagnosis was usually pre-existing amongst these episcleritis patients (15/17; 88\%). During follow-up, one patient developed IBD and one patient was diagnosed with sarcoidosis. The most common systemic diseases associated with scleritis were RA (11/58; 19\%), relapsing polychondritis (2/58; 3\%) and seronegative spondyloarthropathies (2/58; 3\%). No cases of granulomatosis with polyangiitis (GPA) were seen in our study. Diffuse anterior scleritis patients had the highest proportion of systemic disease (14/34; $41 \%$ ) compared to nodular (4/16; $25 \%$ ) and posterior subtypes (2/8; $25 \%$ ). Scleritis was the first manifestation of the underlying systemic disease in $45 \%$ of patients (9/20). Four of these patients were diagnosed with a systemic disease after further investigation at scleritis presentation (RA, three patients; reactive arthritis, one patient), while the other five patients developed a systemic disorder during follow-up of their scleral disease (RA, two patients; relapsing polychondritis, two patients; ankylosing spondylitis, one patient). The median time from initial ocular presentation to a systemic disease diagnosis was 2.6 years (IQR, 0.3-4.4 years).

\subsection{Ocular complications}

During the first 12 months of disease, ocular complications were seen in 3\% (6/184) of eyes with episcleritis compared with $44 \%$ (32/72) of eyes with scleritis ( $p<0.001$; Table 5). All ocular complications among the episcleritis group completely resolved within 1 month from disease onset. 
Table 5: Ocular complications in episcleritis and scleritis eyes within the first 12 months following initial presentation

Ocular Episcleritis n (\% ) ${ }^{\dagger}$

Scleritis n (\% $)^{\dagger}$

complications

\begin{tabular}{lrrrrr}
$\mathbf{N}$ & Simple Nodular & $\begin{array}{l}\mathbf{N} \\
\text { cases }\end{array}$ & $\begin{array}{l}\text { Diffuse } \\
\text { anterior }\end{array}$ & $\begin{array}{l}\text { Nodular } \\
\text { anterior }\end{array}$ & Posterior \\
\hline 172 & 143 & 29 & 58 & 34 & 16
\end{tabular}

All cases

172

Bilateral, cases

Total seen,

143

184

11

29

58

34

eyes

Total attending

$14 \quad 14$

30

72

8

16

12-month visit, eyes

\begin{tabular}{|c|c|c|c|c|c|c|c|c|}
\hline $\begin{array}{l}\text { Any } \\
\text { complication, } \\
\text { eyes }\end{array}$ & $6(3)$ & $5(3)$ & $1(3)$ & $\begin{array}{r}32 \\
(44)\end{array}$ & $20(48)$ & $7(33)$ & $5(56)$ & $<0.001$ \\
\hline \multicolumn{9}{|l|}{$\begin{array}{l}\text { Anterior } \\
\text { segment }\end{array}$} \\
\hline $\begin{array}{l}\text { Corneal } \\
\text { involvement }\end{array}$ & $0(0)$ & $0(0)$ & $0(0)$ & $4(6)$ & $1(2)$ & $3(14)$ & $0(0)$ & 0.006 \\
\hline $\begin{array}{l}\text { Keratitis with } \\
\text { epithelium } \\
\text { intact }\end{array}$ & $0(0)$ & $0(0)$ & $0(0)$ & $1(1)$ & $0(0)$ & $1(5)$ & $0(0)$ & \\
\hline $\begin{array}{l}\text { Peripheral } \\
\text { ulcerative } \\
\text { keratitis }\end{array}$ & $0(0)$ & $0(0)$ & $0(0)$ & $3(4)$ & $1(2)$ & $2(10)$ & $0(0)$ & \\
\hline Anterior uveitis & $1(1)$ & $0(0)$ & $1(3)$ & $\begin{array}{r}12 \\
(17) \\
\end{array}$ & $10(24)$ & $1(5)$ & 1 (11) & $<0.001$ \\
\hline $\begin{array}{l}\text { Ocular } \\
\text { hypertension > } \\
24 \mathrm{mmHg}\end{array}$ & $5(3)$ & $5(3)$ & $0(0)$ & $\begin{array}{r}14 \\
(20)\end{array}$ & $11(26)$ & $2(10)$ & $1(11)$ & $<0.001$ \\
\hline Scleral thinning & $0(0)$ & $0(0)$ & $0(0)$ & $7(10)$ & $2(3)$ & $4(19)$ & $1(11)$ & $<0.001$ \\
\hline \multicolumn{9}{|l|}{$\begin{array}{l}\text { Posterior } \\
\text { segment }\end{array}$} \\
\hline $\begin{array}{l}\text { Serous retinal } \\
\text { detachment }\end{array}$ & $0(0)$ & $0(0)$ & $0(0)$ & $2(3)$ & $0(0)$ & $0(0)$ & $2(22)$ & 0.078 \\
\hline $\begin{array}{l}\text { Other fundus } \\
\text { findings }\end{array}$ & $0(0)$ & $0(0)$ & $0(0)$ & $6(8)$ & $0(0)$ & $0(0)$ & $6(8)$ & $<0.001$ \\
\hline Optic disc & $0(0)$ & $0(0)$ & $0(0)$ & $3(4)$ & $0(0)$ & $0(0)$ & $3(33)$ & \\
\hline
\end{tabular}


swelling

Choroidal folds

$0(0) \quad 0(0)$

$0(0) \quad 4(6)$

$0(0)$

$0(0)$

$4(44)$

† Number of eyes in each complication category represented as a percentage of the number of eyes at initial visit, hence assumes that those patients who did not attend during follow-up did so because they did not develop the complication.

₹ P-value comparison between overall groups of episcleritis and scleritis using Fisher exact test, similarly assumes a patient's non-attendance indicates no complications developed.

Over the 12-month period, concurrent anterior uveitis was seen in 1\% (1/184) of episcleritis eyes compared with $17 \%(12 / 72)$ of scleritis eyes ( $p<0.001)$. Corneal involvement was present in $6 \%(4 / 72)$ of scleritis eyes, of which nodular scleritis was the most common subtype $(3 / 21 ; 14 \%)$, but was not observed in any eye with episcleritis ( $p=0.006$ ). Amongst scleritis eyes affected, one eye had keratitis with epithelium intact and three eyes developed PUK. Ocular hypertension complicated $3 \%(5 / 184)$ of eyes with episcleritis, compared with $20 \%(14 / 72)$ of eyes with scleritis $(p<0.001)$. All episcleritis eyes complicated by OHT were simple. In those with scleritis, OHT most commonly affected scleritis eyes with a diffuse anterior pattern (11/42; $26 \%)$ compared with nodular $(2 / 21 ; 10 \%)$ and posterior $(1 / 9 ; 11 \%)$ subtypes.

Within the affected episcleritis group, two eyes (2/5; 40\%) had OHT at initial presentation that resolved without topical glaucoma therapy. Of the remaining three episcleritis eyes with complications during follow-up, two (2/3; 67\%) eyes developed $\mathrm{OHT}$ whilst on topical steroids. One of these eyes required the addition of glaucoma drops alongside topical steroid therapy. 
Within the scleritis group affected by OHT, five eyes (5/14; 36\%) presented with OHT at initial visit and a further 9 eyes (64\%) developed OHT on follow-up. In those that developed OHT on follow-up, $22 \%$ of eyes (2/9) were on topical steroids at the time of review and $56 \%$ of eyes (5/9) had received a subconjunctival corticosteroid injection within the previous 3 months. Out of all eyes affected by OHT, nine eyes (9/14; 64\%) were prescribed glaucoma drops after the onset of scleritis. Three scleritis eyes $(3 / 14 ; 21 \%)$ that experienced OHT were already on pre-existing topical therapy for primary open-angle glaucoma or pre-existing neovascular glaucoma (one eye, in a patient with proliferative diabetic retinopathy in both eyes).

Seven scleritis eyes (7/72; 10\%) developed scleral thinning over the course of 12 months, with the highest proportion seen in eyes with nodular scleritis $(4 / 21 ; 19 \%)$. Posterior segment complications were only observed in eyes with posterior scleritis, where serous retinal detachment occurred in 2 eyes (2/72; 3\%), optic disc swelling in 3 eyes $(3 / 72 ; 4 \%)$ and choroidal folds in 4 eyes (4/72; 6\%).

\subsection{Treatment of scleritis}

Treatments used at initial presentation and by 12 months following initial presentation for scleritis patients are shown in Table 6. The most common treatment used in the management of scleritis patients at initial presentation were oral non-steroidal anti-inflammatory drugs (NSAIDs) (35/58; 60\%). Oral prednisolone was commenced in 19\% (11/58) of all scleritis patients at initial visit and by 12 months this had increased to 38\% (22/58). Oral prednisolone was used most commonly in those with posterior scleritis (5/8; 63\%). Few scleritis patients (2/58; 3\%) received local depot steroid injections of subconjunctival triamcinolone at initial presentation. By 12 months, subconjunctival triamcinolone injections had been used in $24 \%$ (14/58) of all scleritis patients. Steroid-sparing immunosuppressants were commenced in $10 \%(6 / 58)$ of scleritis patients at initial presentation and by 12 
months were being used in $24 \%$ (14/58) of scleritis patients. Biologics had been commenced in $3 \%(2 / 58)$ of patients with scleritis by the end of 12 months, and in all cases this was adalimumab in combination with methotrexate for diffuse anterior scleritis. Amongst scleritis cases associated with a systemic disease, $45 \%(9 / 20)$ of patients were managed with only NSAIDs, prednisolone or subconjunctival triamcinolone injections, whereas the remaining $55 \%$ (11/20) of patients required steroid sparing agents or biologics by 12 months.

Table 6: Treatments used in scleritis patients within the first 12 months following initial presentation

\begin{tabular}{|c|c|c|c|c|}
\hline \multirow[b]{2}{*}{ Treatment } & \multicolumn{4}{|c|}{ Scleritis n (\%) } \\
\hline & All cases & $\begin{array}{l}\text { Diffuse } \\
\text { anterior }\end{array}$ & $\begin{array}{l}\text { Nodular } \\
\text { anterior }\end{array}$ & Posterior \\
\hline $\mathbf{N}$ cases & 58 & 34 & 16 & 8 \\
\hline \multicolumn{5}{|l|}{$\begin{array}{l}\text { Scleritis treatments at } \\
\text { initial presentation }\end{array}$} \\
\hline Topical steroids & $19(33)$ & $11(32)$ & $7(44)$ & $1(13)$ \\
\hline Oral NSAIDs & $35(60)$ & $24(71)$ & $7(44)$ & $4(50)$ \\
\hline Local depot steroid injection & $2(3)$ & $1(3)$ & $1(6)$ & $0(0)$ \\
\hline Oral prednisolone & $11(19)$ & $5(15)$ & $4(25)$ & $2(25)$ \\
\hline Immunosuppressants & $6(10)$ & $4(12)$ & $1(6)$ & $1(13)$ \\
\hline AZA & $0(0)$ & $0(0)$ & $0(0)$ & $0(0)$ \\
\hline MTX & $6(10)$ & $4(12)$ & $1(6)$ & $1(13)$ \\
\hline MMF & $0(0)$ & $0(0)$ & $0(0)$ & $0(0)$ \\
\hline \multicolumn{5}{|l|}{$\begin{array}{l}\text { Scleritis treatments after } \\
12 \text { months from } \\
\text { presentation }\end{array}$} \\
\hline Topical steroids & $21(36)$ & $13(38)$ & $7(44)$ & $1(13)$ \\
\hline Oral NSAIDs & $47(81)$ & $31(91)$ & $10(62)$ & $6(75)$ \\
\hline Local depot steroid injection & $14(24)$ & $7(21)$ & $4(25)$ & $3(38)$ \\
\hline Oral prednisolone & $22(38)$ & $11(32)$ & $6(38)$ & $5(63)$ \\
\hline Immunosuppressants $^{\dagger}$ & $14(24)$ & $926)$ & $4(25)$ & $1(13)$ \\
\hline AZA & $2(3)$ & $1(3)$ & $1(6)$ & $0(0)$ \\
\hline MTX & $12(21)$ & $824)$ & $3(19)$ & $1(13)$ \\
\hline MMF & $1(2)$ & $1(3)$ & $0(0)$ & $0(0)$ \\
\hline Biologics $^{\ddagger}$ & $2(3)$ & $2(6)$ & $0(0)$ & $0(0)$ \\
\hline
\end{tabular}

NSAIDs, non-steroidal anti-inflammatory drugs; AZA, azathioprine; MTX, methotrexate; MMF, mycophenolate mofetil 
${ }^{\dagger}$ One diffuse anterior scleritis patient trialled more than 1 immunosuppressant (MTX + MMF) over the 12-month period

₹ Biologic (adalimumab) used in 2 patients in combination with MTX 


\section{DISCUSSION}

This is the first study to our knowledge that provides epidemiological data for patients with episcleritis and scleritis in Australia, with characterisation of disease subtype, underlying aetiology, ocular complications and treatments. We found the overall incidence rate was 4.37 per 100,000 person-years for episcleritis and 1.03 per 100,000 person-years for scleritis. Period prevalence over 12-months in this urban Melbourne RVEEH-catchment area was 5.05 per 100,000 persons for active episcleritis and 1.70 per 100,000 persons for active scleritis.

Few studies in episcleritis and scleritis have utilised an appropriate general population denominator. Two previous population-based studies were conducted in U.S medical insurance membership populations and reported higher rates of episcleritis and scleritis than our present study. Six non-randomly selected insurance member communities from Northern California reported 10-fold higher rates for episcleritis and 3-fold higher rates for scleritis relative to our study. ${ }^{3}$ Conversely, a Hawaiian insurance membership population reported a 5 -fold higher incidence of episcleritis but rates of scleritis (4-fold higher incidence) were similar to Northern California when compared with our study. ${ }^{2}$ Different ethnic backgrounds could influence these rate disparities. ${ }^{2,3}$ Northern Californian membership communities were primarily white (41-75\%), followed by blacks (3-34\%) and Asian (6-21\%), ${ }^{8}$ while the studied Hawaiian population was predominantly Asian (40\%) and Pacific I slander $(27 \%)^{2}{ }^{2}$ Although we have limited records of ethnicity in our RVEEH patient cohort, recent data on Greater Melbourne reported $40 \%$ of the population were born overseas, with the leading countries of birth being India and China. ${ }^{9}$ The lower rates of episcleritis and scleritis in our studied population may therefore be the result of higher proportions of South East Asians, however no such data currently exists for the prevalence of episcleritis or scleritis in these populations. 
Most cases of episcleritis in this study were simple, while diffuse anterior scleritis was the most common subtype of scleritis, which is similar to previous reports. 6,10 Interestingly, we found very low numbers of scleritis in older groups aged 65+ years, which differs to findings from previous studies. ${ }^{2,3} \mathrm{It}$ is well-understood that the incidence of RA increases with age and that scleritis relates to periods of poorer systemic control. ${ }^{1}$ As such, advances in disease-modifying agents and newer biologics to treat RA may have reduced the incidence of scleritis in our patient cohort, particularly as RA is the disease most commonly associated with scleritis. ${ }^{1,} 6$, ${ }^{11}$ The lack of any reported cases of necrotising scleritis or scleromalacia perforans in our cohort also suggests better control of these systemic diseases in this era of biologics.

This study confirmed the relatively low rate $(10 \%)$ of associated systemic disease in episcleritis. In contrast, systemic disease was found in $34 \%$ of patients with scleritis in this study. This is higher than the $6 \%$ found by Honik et al. but comparable to $41 \%$ reported by Homayounfar et al. ${ }^{3,11}$ As expected, RA was the most common systemic disease seen (19\%). Interestingly, we did not have any patients with GPA, which has been described as the second most common underlying aetiology after RA in scleritis patients. ${ }^{6,}{ }^{10}$ Given the rarity of GPA, it is possible that this association was not captured in our relatively small group of scleritis patients identified from a 12month study period. Past U.S population-based studies also found no cases of GPA in their patient cohorts using a 12-month study period. ${ }^{3,}{ }^{11}$ Additionally, Fujimoto and associates found that the frequency of GPA was lower in J apan compared with the United Kingdom (annual incidence of 2.1 and 14.3 per million person-years, respectively), ${ }^{12}$ and may be another factor given the higher proportion of Asian and non-European ethnicities in the urban Melbourne population overall. 
Ocular complications were few in episcleritis eyes (3\%). Conversely, $44 \%$ of scleritis eyes developed ocular complications, which is mirrored previously. ${ }^{6}$ Anterior uveitis occurred in $17 \%$ of scleritis eyes, which is comparable to the burden found in previous studies (12-24\%). ${ }^{3,11}$ Ocular hypertension affected $20 \%$ of scleritis eyes and were most commonly seen in those with a diffuse anterior pattern, however this may reflect steroid response given a large proportion received topical steroids (22\%) or subconjunctival corticosteroid injections (56\%). Cataract was likely underreported in our study, as follow-up for complications was limited to 12 months from diagnosis.

According to previous studies, ${ }^{4,13}$ the first-line treatment commonly recommended for scleritis is oral NSAIDs, which is consistent with our study (60\%). Oral prednisolone was used in $19 \%$ of scleritis patients in our study at presentation, and this increased to $38 \%$ by 12 months, similar to previous studies. ${ }^{4}{ }^{11}$ Subconjunctival corticosteroid injections were used in $24 \%$ of scleritis patients in this study during the first 12 months. This likely reflected the emergence of recent long-term multicentre data that demonstrated the effectiveness and safety of subconjunctival triamcinolone in patients with non-necrotising anterior scleritis. ${ }^{14}$ Steroid-sparing immunosuppressants were required by $24 \%$ of our scleritis patients by the 12 -month point, and this was comparable with previous research. ${ }^{4,11}$ Biologics were commenced in $3 \%$ of scleritis patients within 12 months from presentation, which highlights the early introduction of novel agents due to its reported efficacy for refractory scleritis cases and those with systemic disease. ${ }^{13}$

We acknowledge several limitations in this study. First, the retrospective analysis is subject to bias, in particular where patients with ocular complications or systemic disease are more likely to continue to attend their review visits at the RVEEH and this may have led to an apparent overestimation of complications. Second, this analysis only includes patients identified from a single specialised ophthalmology 
tertiary centre. Although the RVEEH is the major referral centre for the provision of ophthalmic care in Melbourne, there is currently no centralised data collection of where all episcleritis and scleritis patients within our population seek treatment nor a practical method to determine this. Instead, individual consumer choice lies at the core of the Australian healthcare system and this is often a composite of public and private health providers. In contrast, the previous population studies performed in the US capitalised on large private health maintenance organisation databases, in which enrolled members received their care almost exclusively through these organisations. ${ }^{2,3}$ Consequently, milder cases of episcleritis and scleritis within our Australian population may have been managed in the community and would not be captured in our study, leading to an underestimation in the true rates. Although we attempted to adjust for this by using the population denominator from areas with higher service delivery by the RVEEH, a fully-unified and inclusive database or medical record across the whole population of Melbourne from which true disease incidence and prevalence rates could be calculated currently remains elusive.

Similarly, patients with severe underlying systemic disease such as granulomatosis with polyangiitis (GPA) or relapsing polychondritis (RP) may have been managed in general hospitals with specialised rheumatology services. This may have led to a further underestimation of the incidence of scleritis overall and those cases associated with an underlying systemic disease, however the number of these cases is still likely to be small.

\subsection{Conclusion}

The incidence and prevalence rates of episcleritis were 4.37 cases per 100,000 person-years and 5.05 cases per 100,000 persons, respectively. The rates for scleritis were 1.03 cases per 100,000 person-years and 1.70 cases per 100,000 persons, respectively. Our findings confirm that episcleritis is usually a benign and 
self-limiting disease, while scleritis is more often associated with ocular complications and systemic autoimmune disease. 


\section{REFERENCES}

1. Okhravi N, Odufuwa B, McCluskey P, Lightman S. Scleritis. Surv Ophthalmol. 2005;50(4):351-63.

2. Homayounfar G, Nardone N, Borkar DS, Tham VM, Porco TC, Enanoria WT, et al. Incidence of scleritis and episcleritis: results from the Pacific Ocular Inflammation Study. AmJ Ophthalmol. 2013;156(4):752-8.

3. Honik G, Wong IG, Gritz DC. Incidence and prevalence of episcleritis and scleritis in Northern California. Cornea. 2013;32(12):1562-6.

4. Jabs DA, Mudun A, Dunn JP, Marsh MJ. Episcleritis and scleritis: clinical features and treatment results. AmJ Ophthalmol. 2000;130(4):469-76.

5. Tuft SJ, Watson PG. Progression of scleral disease. Ophthalmology. 1991;98(4):467-71.

6. Sainz de la Maza M, Molina N, Gonzalez-Gonzalez LA, Doctor PP, Tauber J, Foster CS. Clinical characteristics of a large cohort of patients with scleritis and episcleritis. Ophthalmology. 2012;119(1):43-50.

7. Hart CT, Zhu EY, Crock C, Rogers SL, Lim LL. Epidemiology of uveitis in urban Australia. Clin Exp Ophthalmol. 2019:1-8.

8. Gritz DC, Wong IG. Incidence and prevalence of uveitis in Northern California; the Northern California Epidemiology of Uveitis Study. Ophthalmology. 2004;111(3):491-500.

9. Australian Bureau of Statistics. 2016 Census QuickStats: Greater Melbourne [Internet] 2017 [cited 2017 Sept 20]. Available from:

http://www.censusdata.abs.gov.au/census_services/getproduct/census/2016/quickst at/2GMEL.

10. Akpek EK, Thorne JE, Qazi FA, Do DV, J abs DA. Evaluation of patients with scleritis for systemic disease. Ophthalmology. 2004;111(3):501-6. 
11. Homayounfar G, Borkar DS, Tham VM, Nardone N, Acharya NR. Clinical characteristics of scleritis and episcleritis: results from the pacific ocular inflammation study. Ocul Immunol Inflamm. 2014;22(5):403-4.

12. Fujimoto S, Watts RA, Kobayashi S, Suzuki K, Jayne DR, Scott DG, et al. Comparison of the epidemiology of anti-neutrophil cytoplasmic antibody-associated vasculitis between J apan and the U.K. Rheumatology. 2011;50(10):1916-20.

13. Sainz de la Maza M, Molina N, Gonzalez-Gonzalez LA, Doctor PP, Tauber J, Foster CS. Scleritis Therapy. Ophthalmology. 2012;119(1):51-8.

14. Sohn EH, Wang R, Read R, Roufas A, Teo L, Moorthy R, et al. Long-term, multicenter evaluation of subconjunctival injection of triamcinolone for nonnecrotizing, noninfectious anterior scleritis. Ophthalmology. 2011;118(10):1932-7. 


\section{University Library}

\section{- M M N E R VA A gateway to Melbourne's research publications}

Minerva Access is the Institutional Repository of The University of Melbourne

Author/s:

Thong, LP;Rogers, SL;Hart, CT;Hall, AJ;Lim, LL

Title:

Epidemiology of episcleritis and scleritis in urban Australia

Date:

2020-05-03

Citation:

Thong, L. P., Rogers, S. L., Hart, C. T., Hall, A. J. \& Lim, L. L. (2020). Epidemiology of episcleritis and scleritis in urban Australia. CLINICAL AND EXPERIMENTAL OPHTHALMOLOGY, 48 (6), pp.757-766. https://doi.org/10.1111/ceo.13761.

Persistent Link:

http://hdl.handle.net/11343/275711 